\title{
Análise do modelo de arborização em praças públicas do Município de Fortaleza (Estado do Ceará, Nordeste do Brasil) e sua influência no conforto térmico e estruturas urbanas
}

\author{
José Itamar Frota Júnior*, Israel Teixeira Jesuino, Maerlon Carmo \\ Martins
}

Centro Universitário Estácio do Ceará. Rua Eliseu Beco, 600. Água Fria. FortalezaCE. Brasil (CEP 60810-270). *E-mail: itamarfrota@yahoo.com.br.

Resumo. 0 intenso crescimento territorial e populacional pelo qual as cidades vêm sofrendo, integrado a um mau planejamento e descaso aos espaços verdes, causam danos ao meio ambiente, e consequentemente promovem impactos sobre a saúde, o conforto e as atividades dos citadinos. As praças têm papel fundamental na melhoria do microclima e do conforto térmico, além da melhoria da qualidade do ar, escoamento e absorção das águas pluviais. Logo, faz-se necessário o planejamento da arborização em praças públicas nas grandes metrópoles. A Cidade de Fortaleza não possui um estudo do modelo de arborização adotado em suas praças, assim como, um planejamento que privilegie árvores mais adaptadas ambientalmente e funcionalmente, de preferência nativas, que atendam às necessidades climáticas e sustentáveis. 0 objetivo desse trabalho foi analisar, identificar, quantificar espécies arbóreas existentes em 11 praças públicas do Município de Fortaleza (Estado do Ceará, Nordeste do Brasil), além de estudar as influências das mesmas no conforto térmico e malha urbana. Por meio de excursões a pé realizou-se o estudo, uma planilha padrão foi utilizada para anotação dos dados obtidos nos locais, assim como utilização de máquina fotográfica. Foi utilizado um termômetro digital infravermelho Modelo ST-500 para medição de temperatura em campo. Foram desconsideradas para o estudo, árvores mortas, mudas, arbustos e forração, consideraram-se apenas árvores cujo porte seja maior que $3 \mathrm{~m}$. A aferição de temperatura foi obtida em dias ensolarados e sempre no mesmo horário (11:30 h) em face da cobertura vegetal em diferentes materiais de piso (cimentado e grama), analisou-se o estado fitossanitário das espécies mostrando aquelas que estão potencialmente afetadas por pragas e doenças, além daquelas espécies que interferissem em pisos, sistemas e redes elétricas e hidráulicas dos espaços. Foram registrados 1023 indivíduos distribuídos em 20 famílias, 76 gêneros e 63 espécies nas praças estudadas. Observou-se que o número de espécies exóticas (59,84\%) supera o número de espécies nativas (40,16\%), constatou-se que há grande predomínio da Família Arecaceae $(29,25 \%)$, e em seguida a Família Fabaceae $(22,04 \%)$ em todas as
Recebido:

01/09/2018

Aceito:

$11 / 12 / 2018$

Publicado:

$31 / 12 / 2018$

Acesso aberto

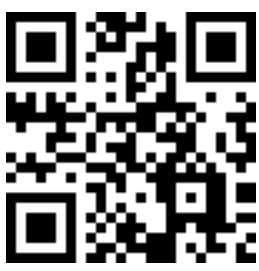

ORCID

(1) 0000-0003-3228-176X José Itamar Frota Júnior

(D) 0000-0003-3737-026X Israel Teixeira Jesuino

(ㄱ) 0000-0002-2332-5663

Maerlon Carmo Martins 
praças estudadas. Detectou-se diferenças significativas nas temperaturas das praças estudadas. Observou-se que há influência das árvores sobre a malha urbana (19,71\%): com ênfase em quebra de calçadas e interferência na fiação elétrica aérea. Constatou-se a influência real da cobertura vegetal no conforto ambiental das praças, no que diz respeito à temperatura e conforto ambiental, imprescindíveis à qualidade de vida nas cidades.

Palavras-chaves: Arborização urbana; Estruturas urbanas; Conforto térmico; Praças públicas; Qualidade de vida.

Abstract. Analysis of the structure model in public premises of Fortaleza Municipality (Ceará State, Northeast Brazil) and its influence on thermal comfort and urban structures. The intense territorial and population growth that cities have been suffering from, combined with poor planning and neglect of green spaces, cause damage to the environment and consequently promote impacts on the health, comfort and activities of city dwellers. The squares have a fundamental role in improving the microclimate and thermal comfort, as well as improving air quality, flow and absorption of rainwater. Therefore, it is necessary to plan afforestation in public squares in large metropolises. The City of Fortaleza does not have a study of the model of afforestation adopted in its squares, as well as a planning that favors trees more adapted environmentally and functionally, preferably native, that meet the climatic and sustainable needs. The objective of this work was to analyze, identify, quantify existing tree species in 11 public squares of Fortaleza (Ceará State, Northeast Brazi), as well as to study their influence on thermal comfort and urban mesh. By means of field trips, the study was carried out, a standard worksheet was used to annotate the data obtained at the sites, as well as the use of a camera. An infrared digital thermometer Model ST-500 was used for field temperature measurement. Dead trees, seedlings, shrubs and forage were disregarded for the study; only trees larger than $3 \mathrm{~m}$ were considered. The temperature gauging was obtained on sunny days and always at the same time (at 11:30 AM) in face of the vegetation cover in different floor materials (cemented and grass), the phytosanitary status of the species was analyzed showing those that are potentially affected by pests and diseases, in addition to those species that interfered in floors, systems and electrical and hydraulic networks of the spaces. There were 1023 individuals distributed in 20 families, 76 genera and 63 species in the studied squares. It was observed that the number of exotic species (59.84\%) exceeds the number of native species (40.16\%), it was verified that there is a large predominance of the Arecaceae Family (29.25\%), and then the Fabaceae Family $(22.04 \%)$ in all the studied squares. Significant differences were detected in the temperatures of the squares studied. It was observed that there is influence of the trees on the urban mesh (19.71\%): with emphasis on the breaking of sidewalks and interference in aerial 
electric wiring. It was verified the real influence of the vegetal cover in the environmental comfort of the squares, with respect to the temperature and environmental comfort, essential to the quality of life in the cities.

Keywords: Urban afforestation; Urban structures; Thermal comfort; Public squares; Quality of life.

\section{Introdução}

Aproximadamente $84,35 \%$ da população brasileira reside em grandes cidades (IBGE, 2010) e isso acontece devido à procura de melhores condições de vida. Esse processo de urbanização relativamente acelerado e sem planejamento, que se iniciou na década de 1960, vem trazendo muitos problemas no que tange a qualidade de vida dos citadinos e impactos na paisagem natural (Ugeda Júnior, 2014).

Segundo Lima (2009), o incremento e a inserção de áreas verdes nos centros metropolitanos desempenham funções sociais, econômicas e ambientais, e a arborização urbana se mostra como uma estratégia para melhorar o conforto térmico nas grandes cidades.

Arborização urbana é uma das grandes alternativas para melhorar o clima de uma cidade, é uma das formas de redução ao aumento do aquecimento da temperatura, da poluição na atmosfera e sonora, contribuindo até na saúde física e mental dos moradores das cidades com grandes espaços de áreas verdes. Além de deixar a cidade mais bela, existe a importância da biodiversidade que uma área verde pode proporcionar, aproximando a natureza cada vez mais dos seres humanos. Segundo Oliveira (2011), a partir da segunda metade do século XX, foi introduzido, no Brasil, a cultura da arborização urbana, consequência do aumento da população nessa época, o que concebeu a necessidade de criação de áreas verdes que proporcionassem lazer e bem-estar psicológico à população.

Um fator importante é a escolha das espécies que irão compor uma determinada área, além do sombreamento e melhora do conforto ambiental, devemos analisar a espécie tanto do ponto de vista singular como no ponto de vista global onde ela irá se portar pelo o todo da paisagem urbana. Segundo Dias (1996) conhecer as espécies arbóreas mais apropriadas para implantação na arborização requer ter conhecimento das características como: velocidade de crescimento, agressividade das raízes, durabilidade, resistência às pragas, doenças, impactos dos pedestres.

A introdução das espécies exóticas no Brasil pelos europeus teve a intenção de suprir necessidades agrícolas ou florestais. Conforme Filgueiras (2005) e Blumenthal (2005) as espécies exóticas se adaptaram muito bem nos países tropicais, inclusive no Brasil, pois nessas localidades há clima e substrato suscetíveis à sua propagação, além da ausência de competidores, predadores e parasitas.

As praças de Fortaleza têm sido locais onde a população utiliza como pontos de encontro e de lazer tendo em vista o resgate desses espaços por ações que a Prefeitura Municipal de Fortaleza tem realizado, no entanto faz-se crucial estudar a cobertura vegetal existente nesses logradouros tendo em vista propiciar conforto térmico aos habitantes e a importância ambiental para a cidade, devido à inexistência de um estudo que contemple a contagem, identificação das espécies existentes em nativas e exóticas, além da observância da escolha da vegetação com vistas ao maior conforto térmico nesses equipamentos.

Diante desse contexto, este trabalho objetivou-se em analisar, identificar, quantificar espécies arbóreas existentes em praças públicas de 
Fortaleza, além de estudar as influências dessas árvores no contexto ambiental e social desses espaços.

\section{Material e métodos}

\section{A área de estudo}

0 estudo foi desenvolvido no Município de Fortaleza, localizado no Nordeste do Estado do Ceará, situado sobre as coordenadas de referência $3^{\circ}$

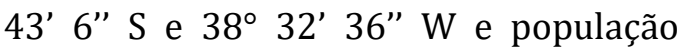
estimada para 2014 de 2.571 .896 habitantes, com área estimada de $314,930 \mathrm{~km}^{2}$ e a densidade demográfica de 7.786,44 (hab/ $\mathrm{km}^{2}$ ) (IBGE, 2010). Grande parte de seu território está inserido na unidade geoambiental de Tabuleiro Pré-Litorâneo, na qual o processo de urbanização já está consolidado, onde a área ocupada por edificações é de aproximadamente $72,01 \%$ da área total, e cerca de 15,45\% da área do município está ocupada por vegetação antropizada com padrão irregular (SEMACE, 2016). Apresenta altitude média de $21 \mathrm{~m}$. 0 clima é do tipo Tropical Chuvoso com Verão Seco, o período chuvoso tem início em janeiro e termina em maio, com temperatura anual média de $26,5^{\circ} \mathrm{C}$.

Neste estudo foram consideradas onze praças principais da cidade de Fortaleza: Praça do Ferreira (0,76 ha), Passeio Público (0,96 ha), Praça José de Alencar (2,02 ha), Praça Clóvis Beviláqua (também conhecida como Praça da Bandeira, 1,10 ha), Praça Luíza Távora (1,5 ha), Praça Bárbara de Alencar (0,1995 ha), Praça Portugal (1,394 ha), Praça Otávio Bonfim $(0,52$ ha), Praça Monte Castelo (também conhecida como Praça João Fontes, 0,385 ha), Praça João Gentil (conhecida popularmente por Praça da Gentilândia, 0,44 ha), e Praça Martins Dourado (0,88 ha).

\footnotetext{
Metodologia do estudo

O levantamento dos dados das praças foi realizado por meio de
}

excursões a pé. Uma planilha padrão foi utilizada para anotações dos dados obtidos nos locais, assim como uma máquina fotográfica Nikon. Foi utilizado um termômetro digital infravermelho Modelo ST-500 para medição de temperatura em campo. Para identificação, quanto à taxonomia das espécies, foram realizadas consultas às literaturas especializadas, como Lorenzi (2002), Lorenzi (2003), e Lorenzi et al. (2018). Quanto ao porte das espécies (pequeno, médio e grande), adotou-se a classificação do Manual de Arborização Urbana da Prefeitura de Fortaleza (2013).

Foram desconsideradas para o estudo, árvores mortas, mudas, arbustos e forração. Consideraram-se apenas árvores cujo porte seja maior que três metros, para serem classificadas taxonomicamente, diferenciando-as em exóticas ou nativas. Para cada indivíduo foi observado a presença de pragas e doenças, influência em equipamentos urbanos e o potencial de conforto ambiental no que diz respeito à temperatura ambiente.

Analisou-se a temperatura do solo das praças, estudadas sob quatro diferentes situações, em solo cimentado sob a sombra da copa das árvores e sob a incidência direta dos raios solares, e em solo natural (areia ou grama) sob a sombra da copa das espécies arbóreas e sob a incidência direta dos raios solares. A aferição das temperaturas foi obtida entre os meses de novembro e janeiro, e em dias ensolarados e no mesmo horário (às 11:30 h). Segundo Moura (2008), a média da temperatura máxima, na Cidade de Fortaleza, corresponde a $30,3^{\circ} \mathrm{C}$, e que nos meses de novembro e dezembro há taxas mais elevadas de temperatura, com $31,1^{\circ} \mathrm{C}$, e que as ilhas de calor na cidade podem chegar a valores maiores que $5{ }^{\circ} \mathrm{C}$, e no período diurno, 7:00 h e 15:00 h, ocorrem com mais intensidade e com maior frequência. 


\section{Resultados e discussão}

\section{e exótica \\ Incidência de vegetação nativa}

Foi registrado um total de 1.023 indivíduos arbóreos, distribuídos em 20 famílias, 76 gêneros e 63 espécies (Tabela 1). A maior parte das árvores registradas é de origem exótica (59,84\%). Na Praça do Ferreira foram observados 67 indivíduos, no Passeio Público, 96, na Praça José de Alencar, 112, na Praça Clóvis Beviláqua, 68, na Praça Luíza Távora, 223, na Praça Bárbara de Alencar, 31, na Praça Portugal, 146, na Praça Otávio Bonfim, 48, na Praça Monte Castelo, 64, na Praça da Gentilândia, 45, e na Praça Martins Dourado, 123.

Com relação ao número de indivíduos por família, os maiores destaques foram para a Aracaceae com predomínio de $29,25 \%$, e em seguida a Fabaceae com aproximadamente 22,04\% do total de indivíduos estudados. Constata-se a expressiva participação da família Aracaceae nas áreas estudadas, embora estudiosos afirmam que a Família Fabaceae é bastante utilizada em arborização urbana (Lindemaier e Santos, 2008).

Na Praça do Ferreira, os maiores destaques, em termos de presença de indivíduos, foram registrados para as espécies Cordia oncocalix (Allemao) (25,40\%), Tecoma stans (L.) Juss. ex Kunth $(25,40 \%)$ e Copernicia prunifera (Miller) H. E. Moore (19,05\%). No Passeio Público, Ficus benjamina L. (23,96\%) e Licania tomentosa (Benth.) Fritsch (21,88\%). Na Praça Luíza Távora, Adonidia merrillii (Becc.) (14,29\%), Cocos nucifera (L.) (10,60\%), e C. prunifera (6,91\%). Na Praça José de Alencar, Syagrus cearenses (Noblick) (18,10\%), Tamarindus indica L. (17,14\%). Na Praça Matos Dourado, C. nucifera (18,35\%), Handroanthus impetiginosus (Mart. ex DC) Mattos (12,84\%), e T. indica (11,10\%). Na Praça Portugal, Carpentaria acuminata (Becc.) $(28,67 \%)$, C. prunifera $(16,08 \%)$, e $H$. impetiginosus $(10,49 \%)$. Na Praça Bárbara de Alencar, Pachira aquatica Aubl. (21,43\%), e Terminalia catappa L. $(17,86 \%)$. Na Praça Otávio Bonfim, L. tomentosa $(21,74 \%)$, e Albizia lebbeck (L.) Benth. (15,22\%). Na Praça da Gentilândia, Mangifera indica L. $(46,67 \%), \quad F$. benjamina $(13,33 \%)$. Na Praça Monte Castelo, L. tomentosa (26,32\%), Pithecellobium dulce (Roxb.) Benth. (12,28\%), e P. aquatica (12,28\%). Já na Praça Clóvis Beviláqua as espécies mais ocorrentes foram, $L$. tomentosa (59,68\%), T. catappa $(6,45 \%)$, e P. dulce $(6,45 \%)$.

Tabela 1. Família botânica, nome popular, número de indivíduos (NI), frequência (Fr\%) e origem das espécies arbóreas e palmeiras encontradas nas 11 principais praças públicas na Cidade de Fortaleza (Estado do Ceará, Nordeste do Brasil).

\begin{tabular}{lcccc}
\hline Família botânica/espécie & Nome popular & NI & Fr (\%) & Origem \\
\hline \multicolumn{1}{c}{ ANACARDIACEAE } & & & & \\
\hline Anacardium occidentale L. & Cajueiro & 5 & $0,49 \%$ & Nativa \\
$\begin{array}{l}\text { Mangifera indica L. } \\
\text { Spondias mombim L. }\end{array}$ & Mangueira & 53 & $5,18 \%$ & Exótica \\
\multicolumn{1}{c}{ APOCYNACEAE } & Cajazeira & 1 & $0,09 \%$ & Nativa \\
\hline \multicolumn{1}{c}{ ARECACEAE } & & & & \\
\hline Plumeria alba L. & Jasmim branco & 9 & $0,88 \%$ & Exótica \\
\hline $\begin{array}{l}\text { Acrocomia aculeata (Jacq.) Lodd. } \text { ex Mart. } \\
\text { Carpentaria acuminata (H. Wendl \& Drude) }\end{array}$ & Macaúba & 3 & $0,29 \%$ & Nativa \\
Becc. & Palmeira & 41 & $4,01 \%$ & Exótica \\
Cocos nucifera (L.) & carpentária & & & \\
& Coqueiro & 58 & $5,67 \%$ & Exótica
\end{tabular}


Tabela 1. Continuação.

\begin{tabular}{|c|c|c|c|c|}
\hline Família botânica/espécie & Nome popular & NI & Fr (\%) & Origem \\
\hline Copernicia prunifera (Miller) H. E. Moore & Carnaúba & 104 & $10,08 \%$ & Nativa \\
\hline Dypsis decaryi (Jum.) Beentje \& J. Dransf. & Palmeira triangular & 38 & $3,72 \%$ & Exótica \\
\hline Dypsis lutescens (H.Wendl.) Beentje \& J. Dransf. & $\begin{array}{c}\text { Palmeira areca- } \\
\text { bambu }\end{array}$ & 8 & $0,78 \%$ & Exótica \\
\hline Licuala grandis $\mathrm{H}$. Wendl. & Palmeira leque & 3 & $0,29 \%$ & Exótica \\
\hline Livistona chinensis (Jacq.) R. Br. & Palmeira chinensis & 21 & $2,05 \%$ & Exótica \\
\hline Phoenix roebelenii O’Brien & Palmeira fênix & 10 & $0,98 \%$ & Exótica \\
\hline Roystonea oleracea (Jacq.) O. F. Cook & Palmeira imperial & 8 & $0,78 \%$ & Exótica \\
\hline Roystonea regia (Kunth) O. F. Cook & $\begin{array}{l}\text { Palmeira real } \\
\text { cubana }\end{array}$ & 10 & $0,98 \%$ & Exótica \\
\hline Syagrus cearenses (Noblick) & Coco-babão & 26 & $2,54 \%$ & Nativa \\
\hline Veitchia merrillii (Becc.) H. E. Moore & Palmeira havaí & 53 & $5,18 \%$ & Exótica \\
\hline Wodyetia bifurcata A. K. Irvine & $\begin{array}{l}\text { Palmeira rabo-de- } \\
\text { raposa }\end{array}$ & 4 & $0,39 \%$ & Exótica \\
\hline \multicolumn{5}{|l|}{ BIGNONIACEAE } \\
\hline Tecoma stans (L.) Kunth & Ipê-mirim & 19 & $1,86 \%$ & Nativa \\
\hline Handroanthus heptaphyllus (Vell.) Mattos & Ipê-roxo & 42 & $4,11 \%$ & Nativa \\
\hline $\begin{array}{l}\text { Handroanthus serratifolius (A. H. Gentry) S. } \\
\text { Grose. }\end{array}$ & Ipê-amarelo & 4 & $0,39 \%$ & Nativa \\
\hline \multicolumn{5}{|l|}{ BIXACEAE } \\
\hline Bixa orellana Lineu & Urucum & 2 & $0,20 \%$ & Nativa \\
\hline \multicolumn{5}{|l|}{ BOMBACACEAE } \\
\hline Pachira aquatica Aubl. & Mongubeira & 46 & $4,50 \%$ & Nativa \\
\hline Syzygium malaccense (L.) Merr. \& L. M. Perry. & Jambeiro & 1 & $0,09 \%$ & Exótica \\
\hline \multicolumn{5}{|l|}{ BORAGINACEAE } \\
\hline Cordia oncocalix (Allemao) & Pau-branco & 22 & $2,15 \%$ & Nativa \\
\hline \multicolumn{5}{|l|}{ CARICACEAE } \\
\hline Carica papaya L. & Mamoeiro & 3 & $0,29 \%$ & Exótica \\
\hline \multicolumn{5}{|l|}{ CASUARINACEAE } \\
\hline Casuarina equisetifolia $\mathrm{L}$. & Casuarina & 11 & $1,13 \%$ & Exótica \\
\hline \multicolumn{5}{|l|}{ CHRYSOBALANACEAE } \\
\hline Licania rigida Benth. & Oiticica & 31 & $3,03 \%$ & Nativa \\
\hline Licania tomentosa (Benth.) Fritsch & Oiti & 70 & $6,84 \%$ & Nativa \\
\hline \multicolumn{5}{|l|}{ COMBRETACEAE } \\
\hline Terminalia catappa L. & Castanhola & 15 & $1,47 \%$ & Exótica \\
\hline \multicolumn{5}{|l|}{ EUPHORBIACEAE } \\
\hline Joannesia princeps Vell. & Indaguaçu & 3 & $0,29 \%$ & Nativa \\
\hline \multicolumn{5}{|l|}{ FABACEAE } \\
\hline Adenanthera pavonina L. & Adenantera & 18 & $1,76 \%$ & Exótica \\
\hline Albizia lebbeck (L.) Benth. & Cássia esponjinha & 25 & $2,44 \%$ & Exótica \\
\hline Anadenanthera macrocarpa (Benth.) & Angico & 1 & $0,09 \%$ & Nativa \\
\hline Caesalpinia leiostachya (Benth.) Ducke 1953 & Jucazeiro & 8 & $0,78 \%$ & Nativa \\
\hline Caesalpinia pulcherrima & Flamboyant-mirim & 1 & $0,09 \%$ & Exótica \\
\hline Cassia fistula $\mathrm{L}$. & Chuva de ouro & 13 & $1,27 \%$ & Exótica \\
\hline Cassia grandis L. f. & Cássia rosa & 3 & $0,29 \%$ & Exótica \\
\hline Clitoria fairchildiana R. A. Howard & Sombreiro & 19 & $1,86 \%$ & Nativa \\
\hline Delonix regia (Hook.) Raf. & Flamboyant & 9 & $0,88 \%$ & Exótica \\
\hline Enterolobium maximum Ducke & Timbaúba & 4 & $0,39 \%$ & Nativa \\
\hline Paubrasilia echinat L. & Pau-brasil & 14 & $1,37 \%$ & Nativa \\
\hline Pithecellobium dulce (Roxb.) Benth & Mata-fome & 23 & $2,25 \%$ & Exótica \\
\hline Tamarindus indica L., 1753 & Tamarindeiro & 31 & $3,03 \%$ & Exótica \\
\hline
\end{tabular}


Tabela 1. Continuação.

\begin{tabular}{|c|c|c|c|c|}
\hline Família botânica/espécie & Nome popular & NI & $\operatorname{Fr}(\%)$ & Origem \\
\hline Senna siamea (Lam.) H. S. Irwin \& Barneby & Cássia de sião & 5 & $0,49 \%$ & Exótica \\
\hline Ziziphus joazeiro Mart. & Juazeiro & 1 & $0,09 \%$ & Nativa \\
\hline \multicolumn{5}{|l|}{ MALVACEAE } \\
\hline Adansonia digitata $\mathrm{L}$. & Baobá & 2 & $0,19 \%$ & Exótica \\
\hline Ceiba glaziovii (Kuntze) K. Schum. & Barriguda & 7 & $0,68 \%$ & Nativa \\
\hline Ceiba speciosa (A. St.-Hil.) Ravena & Paineira & 1 & $0,09 \%$ & Nativa \\
\hline Hibiscus tiliaceus L. & Algodão-da-praia & 17 & $1,66 \%$ & Exótica \\
\hline Sterculia striata St. Hil. et Naud & Xixá do Pará & 8 & $0,78 \%$ & Nativa \\
\hline \multicolumn{5}{|l|}{ MELIACEAE } \\
\hline Azadirachta indica A. Juss. & Nim indiano & 37 & $3,62 \%$ & Exótica \\
\hline \multicolumn{5}{|l|}{ MORACEAE } \\
\hline Ficus elastica Roxb. & Planta da borracha & 2 & $0,20 \%$ & Exótica \\
\hline Ficus benjamina L., 1753 & Ficus benjamim & 38 & $3,71 \%$ & Exótica \\
\hline \multicolumn{5}{|l|}{ MYRTACEAE } \\
\hline Syzygium cumini (L) Skeels & Jamelão & 2 & $0,20 \%$ & Exótica \\
\hline Syzygium malaccense (L.) Merr. \& L. M. Perry & Jambeiro & 2 & $0,20 \%$ & Exótica \\
\hline \multicolumn{5}{|l|}{ SAPOTACEAE } \\
\hline Manilkara zapota (L.) P. Royen & Sapotizeiro & 1 & $0,09 \%$ & Exótica \\
\hline \multicolumn{5}{|l|}{ STRELITZIACEAE } \\
\hline Ravenala madagascariensis Sonn. & Árvore do viajante & 5 & $0,49 \%$ & Exótica \\
\hline \multicolumn{5}{|l|}{ URTICACEAE } \\
\hline Cecropia glaziovii Snethl. & Torem & 2 & $0,20 \%$ & Nativa \\
\hline Total & & 1.023 & $100 \%$ & - \\
\hline
\end{tabular}

Não se recomenda que a frequência de uma única espécie arbórea ultrapasse os $15 \%$, pois é bastante atrativo criar diferentes pontos de interesse, além do que isso pode criar um ambiente propício ao ataque de pragas e doenças, bem como a competividade pode gerar declínio populacional das espécies de menor proporção (Redin et al., 2010).

Do total de espécies encontradas nas onze praças, foi possível observar que as espécies exóticas representam maioria absoluta, com aproximadamente 93\%. Moro (2011), ao analisar o número de espécies exóticas em dois bairros de Fortaleza, Jardim América e Benfica, observou que há uma grande representatividade da espécie F. benjamina, entretanto essa não é a única preocupação, pois nesse estudo constatou-se que a cada nove entre dez espécies arbóreas são de origem exótica (95\%).
Com relação ao número de indivíduos encontrados nas praças estudadas, há uma ligeira diferença em relação às espécies nativas e exóticas, $40,16 \%$ e $59,84 \%$, respectivamente. Plantas exóticas são bastante cultivadas em Fortaleza, um dos principais motivos é que a população de Fortaleza não tem conhecimento de quais são as espécies nativas regionais, e como consequência, não podem contribuir efetivamente para a conservação biológica (Moro, 2011).

$\mathrm{Na}$ totalidade das praças avaliadas, as quatro espécies exóticas mais representativas, são: $M$. indica (53 indivíduos), A. merrillii (53 indivíduos), C. acuminata (41 indivíduos), F. benjamina (38 indivíduos).

\section{Influência do indivíduo arbóreo sobre o conforto térmico \\ Detectou-se uma diferença significativa nas temperaturas do solo das praças estudadas, sob a sombra da copa das árvores, e sob a incidência}


direta dos raios solares (Tabela 2). De acordo com Barbosa (2005) a vegetação intervém na temperatura, mas não só na temperatura, como também na umidade e velocidade do ar e radiação. Resende (2011) afirma que a copa das árvores minimiza a incidência direta de raios solares, contribuindo assim com a melhora do microclima.

Quanto aos resultados obtidos com as medições de temperaturas do solo cimentado sob a incidência direta dos raios solares das áreas analisadas, foi possível observar que duas das onze praças, Praça Bárbara de Alencar $\left(49,2^{\circ} \mathrm{C}\right)$ e Praça João Gentil $\left(49,1^{\circ} \mathrm{C}\right)$ apresentaram temperaturas superiores a $48^{\circ} \mathrm{C}$, e apenas uma praça, Praça José de Alencar $\quad\left(34,7^{\circ} \mathrm{C}\right) \quad$ apresentou temperatura inferior a $35^{\circ} \mathrm{C}$, sob o mesmo cenário. Por outro lado, quando se avaliou a temperatura do solo cimentado sob a sombra da copa das árvores, foi possível constatar que nas praças onde a temperatura foi superior a $48{ }^{\circ} \mathrm{C}$, houve uma redução de aproximadamente $30 \%$ da temperatura do solo. Esses dados corroboram com o fato de que as espécies arbóreas utilizadas na arborização urbana reduzem bastante os efeitos da radiação solar e oferecem conforto térmico ao ambiente.

Tabela 2. Média das temperaturas nas praças: A-P. Monte Castelo; B-P. Otávio Bonfim; C-P. Bárbara de Alencar; D-P. Luiza Távora; E-P. Portugal; F-P. Gentilândia; G-P. Martins Dourado; H-Passeio Público; I-P. do Ferreira; J-P. José de Alencar; L-P. da Bandeira

\begin{tabular}{|c|c|c|c|c|}
\hline & \multicolumn{2}{|c|}{$\begin{array}{l}\text { Solo impermeabilizado } \\
\text { (cimentado, ladrilho) }\end{array}$} & \multicolumn{2}{|c|}{$\begin{array}{c}\text { Solo natural } \\
\text { (grama ou areia) }\end{array}$} \\
\hline \multicolumn{5}{|c|}{ Média de temperatura $\left({ }^{\circ} \mathrm{C}\right)$} \\
\hline & $\begin{array}{l}\text { Sob ação dos } \\
\text { raios solares }\end{array}$ & $\begin{array}{l}\text { Sob sombra das } \\
\text { árvores }\end{array}$ & $\begin{array}{c}\text { Sob ação dos raios } \\
\text { solares }\end{array}$ & $\begin{array}{c}\text { Sob sombra das } \\
\text { árvores }\end{array}$ \\
\hline A. & $40,1^{\circ} \mathrm{C}$ & $28,8^{\circ} \mathrm{C}$ & $34,6^{\circ} \mathrm{C}$ & $27,6^{\circ} \mathrm{C}$ \\
\hline B. & $41,4^{\circ} \mathrm{C}$ & $42,6^{\circ} \mathrm{C}$ & $31,5^{\circ} \mathrm{C}$ & $30,4^{\circ} \mathrm{C}$ \\
\hline C. & $49,2^{\circ} \mathrm{C}$ & $45,7^{\circ} \mathrm{C}$ & $28,2^{\circ} \mathrm{C}$ & $25,6^{\circ} \mathrm{C}$ \\
\hline D. & $44,4^{\circ} \mathrm{C}$ & $31,6^{\circ} \mathrm{C}$ & $34,5^{\circ} \mathrm{C}$ & $28,8^{\circ} \mathrm{C}$ \\
\hline E. & $38,1^{\circ} \mathrm{C}$ & $36,7^{\circ} \mathrm{C}$ & $30,2^{\circ} \mathrm{C}$ & $26,1^{\circ} \mathrm{C}$ \\
\hline F. & $49,1^{\circ} \mathrm{C}$ & $41,2^{\circ} \mathrm{C}$ & $32,6^{\circ} \mathrm{C}$ & $30,1^{\circ} \mathrm{C}$ \\
\hline G. & $47,6^{\circ} \mathrm{C}$ & $37,8^{\circ} \mathrm{C}$ & $26,5^{\circ} \mathrm{C}$ & $25,3^{\circ} \mathrm{C}$ \\
\hline H. & $40,9^{\circ} \mathrm{C}$ & $37,1^{\circ} \mathrm{C}$ & $22,8^{\circ} \mathrm{C}$ & $22,8^{\circ} \mathrm{C}$ \\
\hline I. & $37,1^{\circ} \mathrm{C}$ & $35,4^{\circ} \mathrm{C}$ & $26,9^{\circ} \mathrm{C}$ & $26,4^{\circ} \mathrm{C}$ \\
\hline J. & $34,7^{\circ} \mathrm{C}$ & $33,8^{\circ} \mathrm{C}$ & $26,9^{\circ} \mathrm{C}$ & $26,4^{\circ} \mathrm{C}$ \\
\hline L. & $41,5^{\circ} \mathrm{C}$ & $40,6^{\circ} \mathrm{C}$ & $29,3^{\circ} \mathrm{C}$ & $27,8^{\circ} \mathrm{C}$ \\
\hline
\end{tabular}

\section{Identificação de problemas fitossanitários e interferência em equipamentos urbanos}

A inserção de árvores em áreas verdes e arborização viária deve-se ser bem planejada, do contrário, pode ocorrer problemas inoportunos no futuro, logo deve-se, na implantação da espécie arbórea, considerar o local para o plantio, a escolha da espécie, e as características do meio ao redor da espécie (CEMIG, 2011).

Nas praças estudadas foram encontradas 63 espécies de porte arbóreo distribuídas em 20 famílias. As famílias mais representativas foram Arecaceae (369 indivíduos), seguida de Fabaceae (175 indivíduos), Chrysobalanaceae (101 indivíduos), Bignoniaceae (65 indivíduos), 
Anarcardiaceae (59 indivíduos) e Moraceae (40 indivíduos).

Pode-se notar que não há uma composição florística bem diversificada nas praças estudadas, e que não houve um estudo prévio na implantação de espécies arbóreas. Segundo Redin et al. (2010), é apropriado que a frequência de um indivíduo arbóreo não ultrapasse os $15 \%$ em uma determinada área. Observou-se, na maioria das praças, o uso demasiado das espécies L. tomentosa (Passeio Público, 21,88\%; Praça Otávio Bonfim, 21,74\%; Praça Monte Castelo, 26,32\%. Praça Clóvis Beviláqua, 59,68\%), F. benjamina (Passeio Público, 23,96\%), M. indica (Praça da Gentilândia,
46,67\%), e P. aquatica (Praça Bárbara de Alencar, 21,34\%).

0 oiti (L. tomentosa) possui uma copa densa, consequentemente pode apresentar uma boa área de sombreamento, entretanto, suas raízes são superficiais, causando problemas de quebra de calçadas (Figura 1), e interferência em edificações próximas (Figura 2) (Moura e Santos, 2009). A Mangueira (M. indica) é outra espécie que causa preocupação sobre a sua utilização em praças públicas, apesar de ser uma espécie perenifólia, e gerar um bom sombreamento, ela produz frutos grandes, e estes podem gerar prejuízos a veículos estacionados, e aos pedestres.
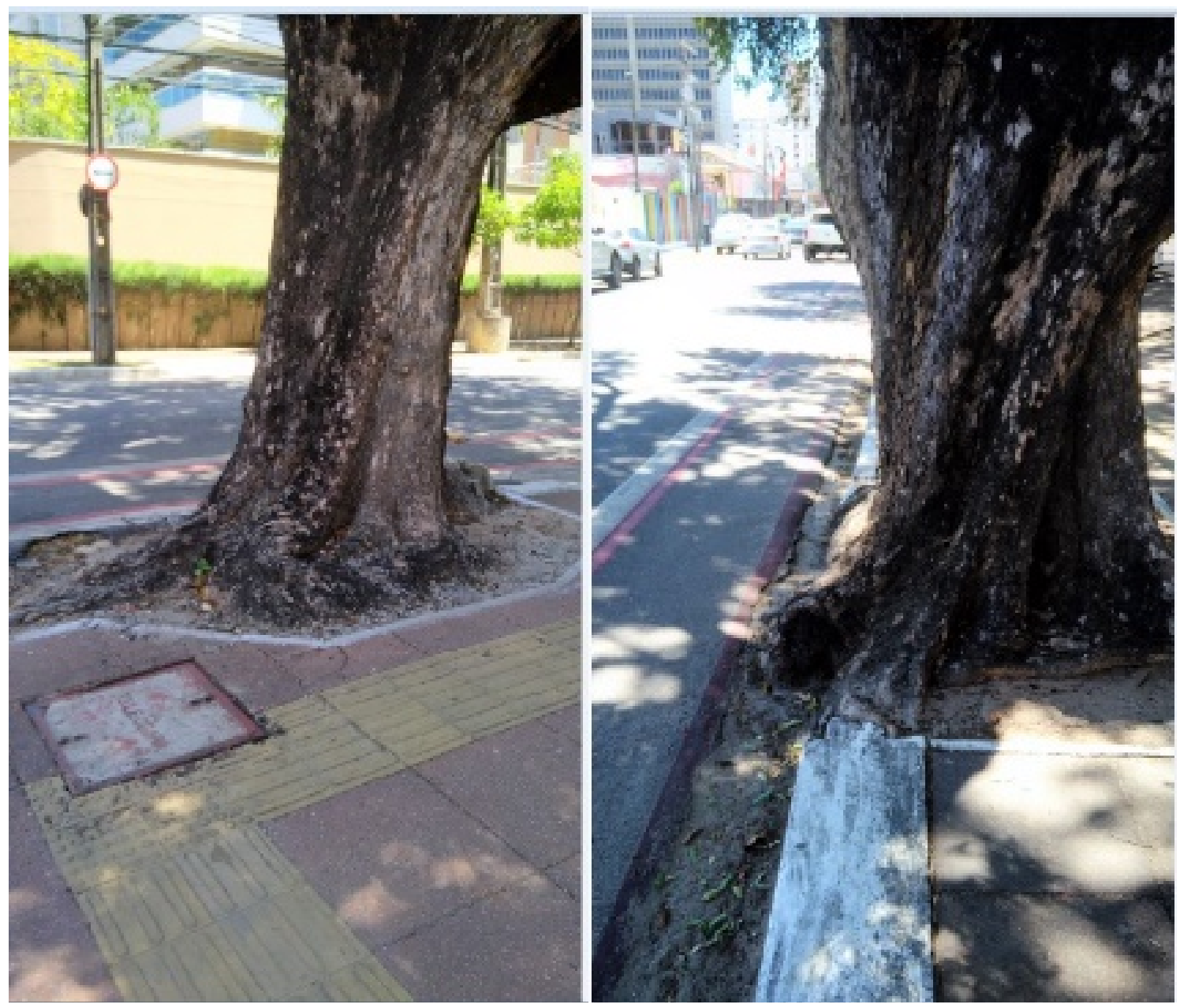

Figura 1. Conflito com a calçada na Praça Luíza Távora, mostrando os danos que a L. tomentosa provoca. 


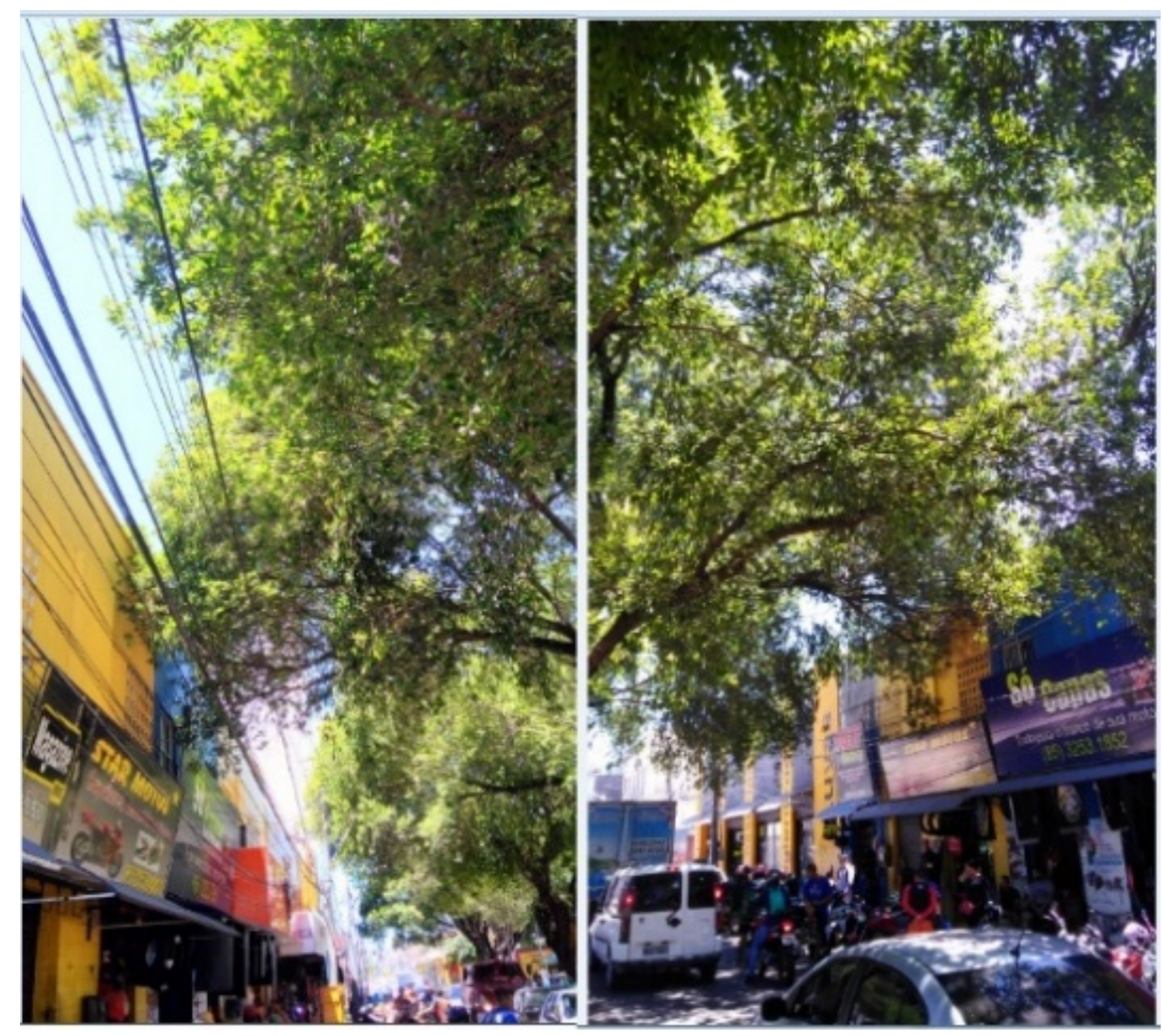

Figura 2. Conflitos na Praça da Bandeira, interferência da L. tomentosa nas edificações próximas.

Os aspectos fitossanitários possibilitam examinar as condições fitossanitárias das espécies arbóreas analisadas. Nas praças estudadas, observou-se que os danos causados por insetos correspondiam a $34,47 \%$ dos ataques, e que o inseto Dactylopius coccus (Costa), cochonilha (Figura 3), representou $35,42 \%$ desses ataques; pragas e doenças representou $24,57 \%$, a erva-de-passarinho, foi a espécie mais proeminente em relação a infestação de parasitas nas árvores, representou 2,4\% de presença em todas as espécies analisadas. 


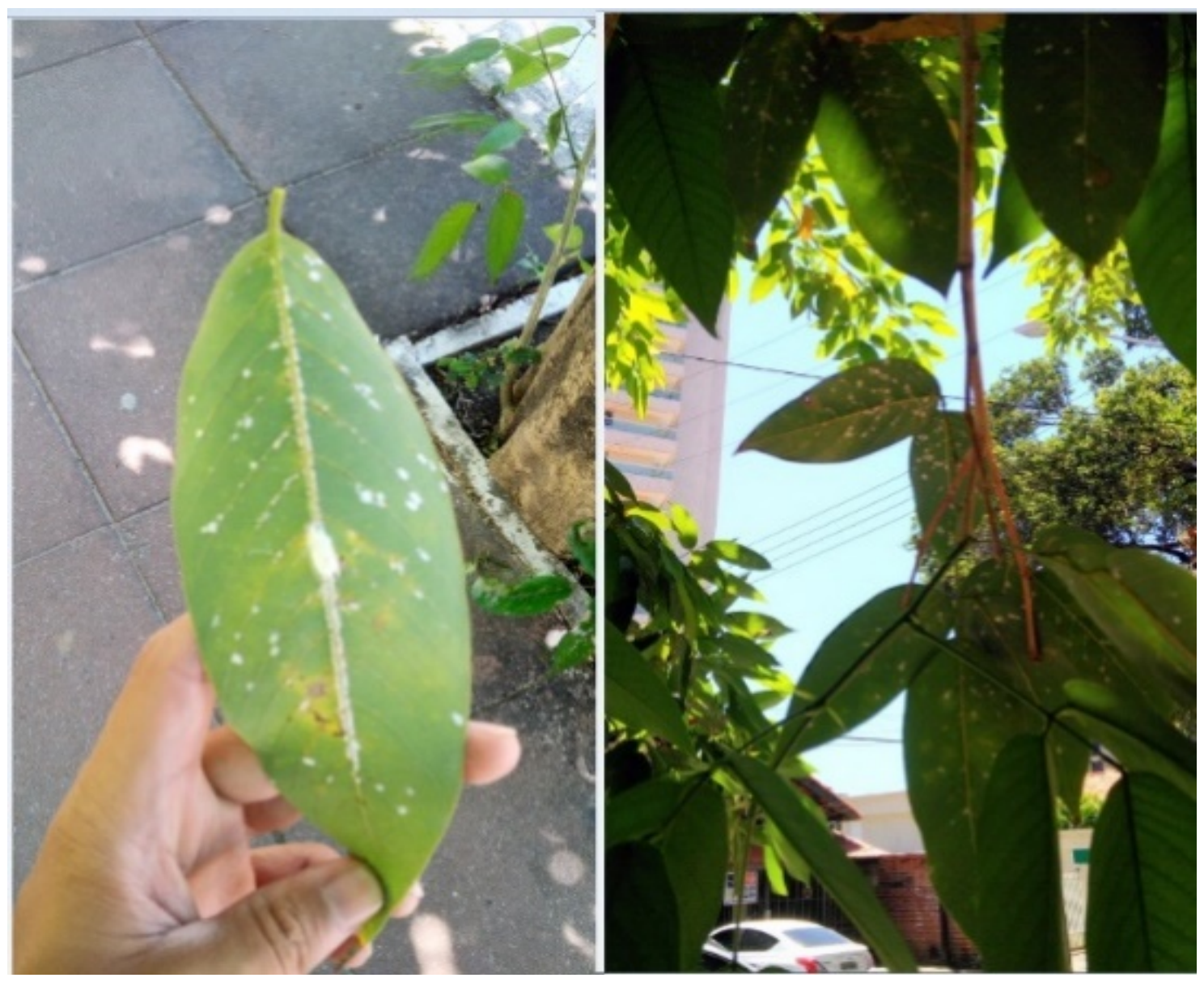

Figura 3. Relato da incidência de pragas encontrada na Praça Luíza Távora, mostrando o ataque da cochonilha à C. fairchildiana.

Outro problema bastante recorrente na arborização urbana brasileira é o plantio de espécies que apresentam sistema radicular superficial. Espécies com características de raiz superficial provocam diversos problemas na local onde são implantadas, que são quebra de calçadas e podem comprometer a estrutura de edificações próximas (Santos et al., 2015). Neste estudo, dentre as espécies que apresentam como características sistema radicular superficial pode-se observar que $11,43 \%$ das espécies avaliadas apresentaram conflitos com meio devido a esse fator. A espécie com o maior número de indivíduos causando problemas foi a $F$. benjamina (ficus) seguido da P. dulce (mata-fome) e da $L$. tomentosa (oiti) (Figura 4).
Foi observado que apenas $16,24 \%$ das espécies presentes nas praças analisadas estão interferindo na fiação elétrica aérea, a espécie mais representativa causando esse transtorno foi a $L$. tomentosa $(34,56 \%) M$. indica $(24,78 \%), P$. aquatica $(14,32 \%)$ e $A$. pavonina $(8,92 \%)$ (Figura 5). Segundo Velasco et al. (2006), o conflito entre árvores e redes de distribuição elétrica pode trazer diversos transtornos à população, sendo: queda de energia, e até expor a população a riscos com choques elétricos, e a autora expõe uma outra maneira de distribuição de energia elétrica, que se torna muita mais vantajosa do que a distribuição por meio de redes de fiação aérea, que são as redes de distribuição subterrâneas. 


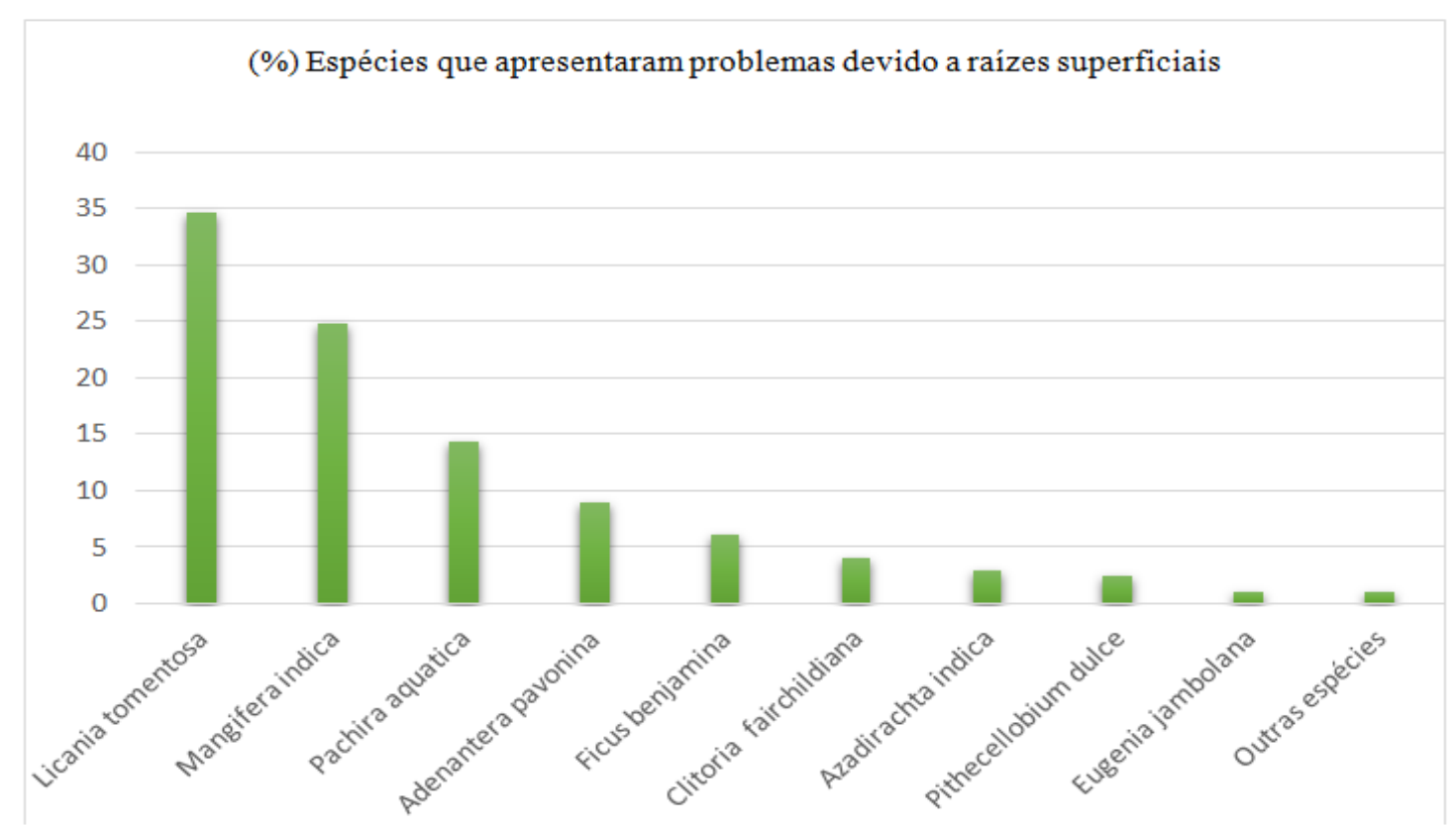

Figura 4. Porcentagem de árvores por espécie que mais apresentaram problema devido à superficialidade das raízes nas 11 praças públicas da Cidade de Fortaleza (Estado do Ceará, Nordeste do Brasil).

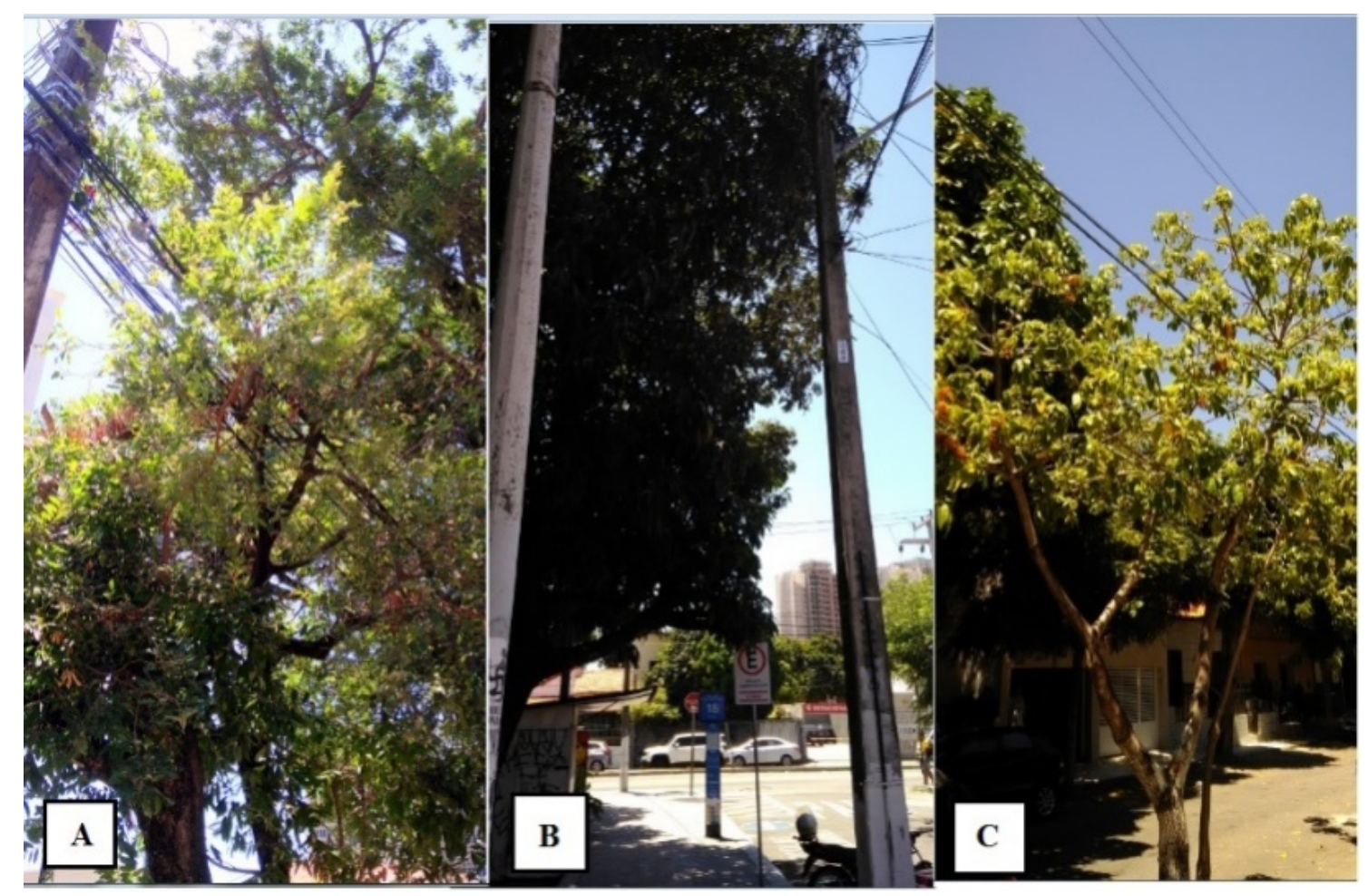

Figura 5. Conflitos com a fiação aérea elétrica. A - L. tomentosa em conflito com fiação aérea elétrica; B - M. indica em conflito com a fiação aérea elétrica; C - P. aquatica em conflito com a fiação aérea elétrica. 


\section{Conclusão}

A maioria das espécies encontradas foi exótica. Constatou-se que há pouca diversidade de espécies arbóreas haja vista que a família Arecaceae represente $29,25 \%$ e a família Fabaceae represente $22,04 \%$ das espécies analisadas. É aconselhável que haja o plantio de novas espécies, preferencialmente nativas.

É importante salientar que nesses equipamentos há visitação de pessoas e um grande fluxo de veículos ao seu redor, logo é necessário que haja mais atenção no que condiz o estado fitossanitário das espécies arbóreas, pois árvores praguejadas ou doentes podem provocar acidentes à população por queda de galhos sobre os carros. Além disso, notou-se a influência de algumas espécies seja por quebra de calçadas pelas raízes, seja pela interferência com a rede ou fiação elétrica. Recomenda-se que a rede elétrica aérea seja implantada, de preferência, nas calçadas oeste e norte, árvores de porte médio sejam implantadas nas calçadas leste e sul, e sob essa fiação sejam árvores de pequeno porte, e no caso de árvores de porte inadequado para plantio sob fiação, cujas copas estejam em contato a rede, o ideal seria a implantação de redes protegidas, isoladas ou compactas, devese atentar também ao tipo e tamanho das raízes das espécies, principalmente aquelas do tipo "tabular", nesse sentido, o espaço recomendado deve ser amplo.

Nas análises de temperatura do solo entre ambientes sombreados pelas árvores em relação às não sombreadas, constatou-se que a vegetação arbórea tem influência sobre a redução de temperatura, e consequentemente melhora no conforto térmico.

Espera-se realizar o levantamento de espécies arbóreas em outras praças de Fortaleza e elaborar um manual para cada praça onde se poderá sugerir espécies mais adequadas, que propiciem maior conforto térmico, bem como, criação de programas de educação ambiental junto à comunidade, dandolhes subsídio para contribuírem efetivamente à conservação ambiental e respeito às árvores.

\section{Conflito de interesses}

Os autores declaram não haver conflito de interesses.

\section{Referências}

Barbosa, R. V. R. Áreas verdes e qualidade térmica em ambientes urbanos: estudo em microclimas de Maceió (AL). São Paulo: Universidade de São Paulo, 2005. (Dissertação de mestrado). Disponível em: <http://www.teses.usp.br/teses/disponiveis /18/18139/tde-03062006-142516/ptbr.php>. Acesso em: 24 jan. 2018.

Blumenthal, D. Interrelated causes of plant invasion. Science, v. 310, n. 5746, p. 243-244, $2005 . \quad$ https://doi.org/10.1126/science. 1114851

CEMIG - Companhia Energética de Minas Gerais. Manual de arborização. Belo Horizonte: CEMIG, Fundação Biodiversitas, 2011.

Dias, R. A importância da arborização urbana. Anais do I Seminário de Arborização Urbana no Rio de Janeiro, 1996.

Filgueiras, T. S. Asiáticas no Brasil: gramíneas (Poaceae) introduzidas da Ásia. Eugeniana, v. 28 p. 3-18, 2005.

Fortaleza. Manual de arborização: procedimentos técnicos para plantio, transplantio, poda e corte. Fortaleza: SEUMA, 2013. Disponível em: <https://urbanismoemeioambiente.fortaleza .ce.gov.br/images/urbanismo-e-meioambiente/manuais/manual_arborizacao.pdf> . Acesso em: 25 nov. 2017.

IBGE - Instituto Brasileiro de Geografia e Estatística. Censo 2010. Disponível em: <http://www.ibge.gov.br>. Acesso em: 27 jul. 2018.

Lima, R. M. C. Avaliação da arborização urbana do Plano Piloto. Brasília: Universidade de Brasília 2009. (Dissertação de mestrado). Disponível em: <http://repositorio.unb.br/handle/10482/5 858>. Acesso em: 08 set. 2017.

Lindenmaier D. S.; Santos N. O. Arborização urbana das praças de Cachoeira do Sul RS- 
Brasil: fitogeografia, diversidade e Índice de áreas verdes. Pesquisas, Botânica, n. 59, p. 307-320, 2008. Disponível em: <http://www.anchietano.unisinos.br/publica coes/botanica/botanica59/artigo17.pdf>.

Acesso em: 18 dez. 2017.

Lorenzi, H. Árvores brasileiras: manual de identificação e cultivo de plantas arbóreas nativas do Brasil. Nova Odessa: Plantarum, 2002.

Lorenzi, H. Árvores exóticas no Brasil: madeireiras, ornamentais e aromáticas. Nova Odessa: Plantarum, 2003.

Lorenzi, H.; Bacher, L. B.; Torres, M. A. V. Árvores e arvoretas exóticas no Brasil: madeireiras, ornamentais, aromáticas. Nova Odessa: Plantarum, 2018.

Moro, M. F.; Westerkamp, C. The alien street trees of Fortaleza (NE Brazil): Qualitative observations and the inventory of two districts. Ciência Florestal, v. 21, n. 4, p. 789798, 2011. https://doi.org/10.5902/1980 50984524

Moura, M. O. 0 clima urbano de Fortaleza sob o nível do campo térmico. Fortaleza: Universidade Federal do Ceará, 2008. (Dissertação de mestrado). Disponível em: <http://repositorio.ufc.br/bitstream/riufc/8 232/1/2008_dis_momoura.pdf>. Acesso em: 04 jul. 2018.

Moura, T. A.; Santos, V. L. L. V. Levantamento quali-quantitativo de espécies arbóreas e arbustivas na arborização viária urbana dos bairros centro e centro norte, Várzea Grande, Mato Grosso, Brasil. Revista da Sociedade Brasileira de Arborização Urbana, v. 1, n. 1, p. 97-117, 2009. Disponível em: <http://silvaurba.esalq.usp.br/revsbau/artig os_cientificos/artigo74-versao_ publicacao.pdf>. Acesso em: 04 jul. 2018.

Oliveira, A. S. Influência da vegetação arbórea no microclima e uso de praças públicas. Cuiabá: Universidade Federal de Mato Grosso, 2011. (Tese de doutorado). Disponível em: <http://www.pgfa.ufmt.br/ index.php/br/utilidades/teses/189-angela- santana-de-oliveira-1/file>. Acesso em: 01 ago. 2018.

Redin C. G.; Vogel, C.; Trojahn, C. D. P.; Gracioli, C. R.; Longhi, S. J. Análise da arborização urbana em cinco praças do Município de Cachoeira do Sul, RS. Revista da Sociedade Brasileira de Arborização Urbana, v. 5, n. 3, p. 149-164, 2010.

Resende, O. M. Arborização urbana. Barbacena: Universidade Presidente Antônio Carlos, 2011. (Monografia de bacharelado). Disponível em: <http://www.unipac.br/ site/bb/tcc/tcc-9c9e0ecfc01dfebdd0ae3785 183c0936.pdf>. Acesso: 09 set. 2017.

Santos, C. Z. A.; Ferreira, R. A.; Santos, L. R.; Santos, L. I.; Gomes, S. H.; Graça, D. A. S. Análise qualitativa da arborização urbana de 25 vias públicas Cidade de Aracaju-SE. Ciência Florestal, v. 25, n. 3, p. 751-763, 2015. https://doi.org/10.5902/19805098 19678

SEMACE - Secretaria do Meio Ambiente do Ceará. Reestruturação e atualização do mapeamento do projeto zoneamento ecológico-econômico do Ceará: Zona Costeira e Unidades de Conservação Costeiras. Fortaleza: Governo do Estado do Ceará, 2016. Disponível em: <http://www.semace.ce.gov.br/wp-content/ uploads/2016/12/RELATÓRIOMAPEAMENTO-POTENCIALIDADE.pdf>. Acesso em: 17 jul. 2018.

Ugeda Júnior, J. C. Planejamento da paisagem e planejamento urbano: reflexões sobre a urbanização brasileiro. Revista MatoGrossense de Geografia, v. 17, n. 1, p. 101116, 2014. Disponível em: <http://periodicoscientificos.ufmt.br/ojs/ind ex.php/geografia/article/view/764>. Acesso em: 17 jul. 2018.

Velasco, G. D. N.; Lima, A. M. L.; Couto, H. T. Z. Análise comparativa dos custos de diferentes redes de distribuição de energia elétrico no contexto da arborização urbana. Revista Árvore, v. 30, n. 4, p.679-686, 2006. https://doi.org/10.1590/S010067622006000400022 